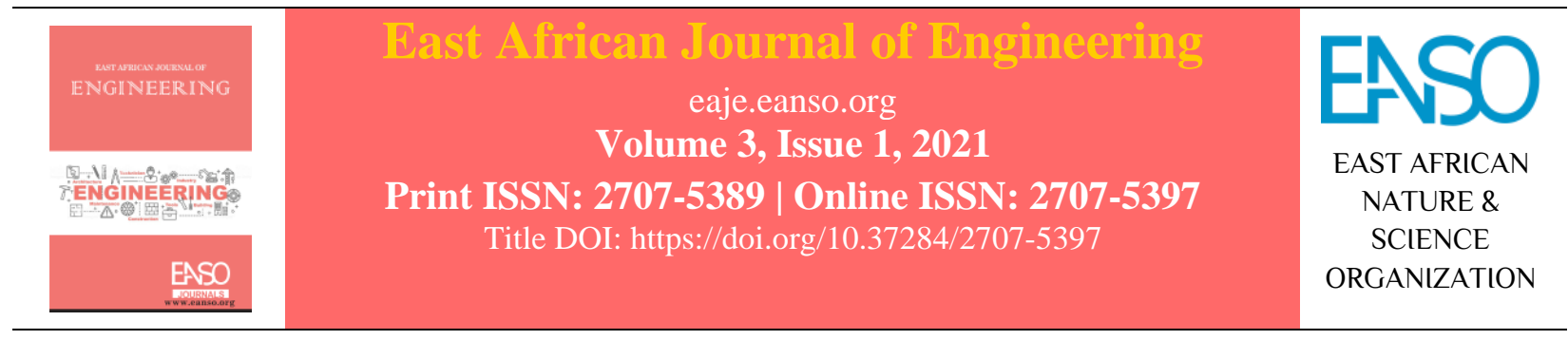

Original Article

\title{
The Mechanical and Binding Potentials of Fresh Cow Dung (FCD) for Gravel Roads Construction.
}

\author{
Anthony Mugendi. Nyagah ${ }^{1}$, Prof. Sixtus Kinyua Mwea, PhD ${ }^{l} \&$ Prof. Francis John Gichaga, PhD ${ }^{l}$ \\ ${ }^{1}$ Department of Civil and Construction Engineering, University of Nairobi, P. O. Box 30197 - 00200 Nairobi, Kenya. \\ * Author for Correspondence ORCID: 0000-0001-6366-2544; Email: tonyrwigi@students.uonbi.ac.ke
}

Article DOI: https://doi.org/10.37284/eaje.3.1.350

\section{Publication Date: ABSTRACT}

28 June 2021 Among the developing nations, unpaved (gravel and earth) roads form a disproportionately large percentage of the road network when compared to

Keywords: the paved roads. For instance, in Kenya earth roads account for $47 \%$ of the road network, while the gravel roads account for about $38 \%$. The most significant problem associated with gravel and earth roads is dust emission, which contributes to the deterioration of the road surface. In addition, the dust causes road safety, human health and the environmental quality issues. In order to minimize dust emission dust suppressants are applied annually. Dust suppressants, for example, Magnesium or Calcium Chlorides solutions are expensive and hence not widely used in developing countries like Kenya. In many Kenyan rural homes and in most African countries, fresh cow dung (FCD) is used as dust suppressants in madhouses. Therefore, this study seeks to explore the mechanical and binding potentials of FCD for gravel roads construction as a dust suppressant, improvement of mechanical and resilience properties of lateritic soils for gravel roads construction. The effect of FCD on gravel soils was determined at various percentages $(0 \%, 3 \%, 6 \%, 9 \%$ and $12 \%$ ) by weight. The Index properties, compaction properties, plasticity requirements and bearing strengths \{Unconfined Compressive Strength (UCS) and California Bearing Ratio (CBR) \} were determined. The results show that Maximum Dry Density (MDD) reduced while the Optimum Moisture Content (OMC) increased with the increase in dosages of FCD. The UCS test results were $257 \mathrm{kN} / \mathrm{m}^{2}(0 \%), 257 \mathrm{kN} / \mathrm{m}^{2}(3 \%), 300 \mathrm{kN} / \mathrm{m}^{2}(6 \%)$, $267 \mathrm{kN} / \mathrm{m}^{2}(9 \%)$ and $213 \mathrm{kN} / \mathrm{m}^{2}(12 \%)$ while, the CBR test results were $21 \%$, $39 \%, 54 \%, 34 \%$, and $24 \%$ for $0 \%, 3 \%, 6 \%, 9 \%$ and $12 \%$. The research concludes that FCD at $6 \%$ by weight can be used for mechanical stabilization of gravel soils for road construction. FCD is cheaper, readily available, sustainable and environmentally friendly. This will go a long way in the economic development of low and middle-income countries. 


\section{APA CITATION}

Nyagah, A. M., Mwea, S. K., \& Gichaga, F. J. (2021). The Mechanical and Binding Potentials of Fresh Cow Dung (FCD) for Gravel Roads Construction. East African Journal of Engineering, 3(1), 22-32. https://doi.org/10.37284/eaje.3.1.350

\section{CHICAGO CITATION}

Nyagah, Anthony Mugendi, Sixtus Kinyua Mwea, \& Francis John Gichaga. 2021. "The Mechanical and Binding Potentials of Fresh Cow Dung (FCD) for Gravel Roads Construction”. East African Journal of Engineering 3 (1), $22-32$. https://doi.org/10.37284/eaje.3.1.350.

\section{HARVARD CITATION}

Nyagah, A. M., Mwea, S. K., and Gichaga, F. J. (2021) "The Mechanical and Binding Potentials of Fresh Cow Dung (FCD) for Gravel Roads Construction”, East African Journal of Engineering, 3(1), pp. 22-32. doi: 10.37284/eaje.3.1.350.

\section{IEEE CITATION}

A. M., Nyagah., S. K Mwea., \& Gichaga, F. J "The Mechanical and Binding Potentials of Fresh Cow Dung (FCD) for Gravel Roads Construction," EAJE, vol. 3, no. 1, pp. 22-32, Jun. 2021.

\section{MLA CITATION}

Nyagah, Anthony Mugendi, Sixtus Kinyua Mwea, \& Francis John Gichaga. "The Mechanical and Binding Potentials of Fresh Cow Dung (FCD) for Gravel Roads Construction.” East African Journal of Engineering, Vol. 3, no. 1, Jun. 2021, pp. 22-32, doi:10.37284/eaje.3.1.350.

\section{INTRODUCTION}

Low volume rural road (LVRR) networks in SubSaharan Africa (SSA) form up to $80 \%$ of a country's total road network and are critical to the socioeconomic wellbeing of the rural communities they serve. However, in many countries in SSA, over 98\% of LVRRs are made from earth or gravel and are therefore impassable during the rainy season (Ngezahayo et al., 2019).

In Africa most of the rural roads are gravel and earth roads. Good condition of the rural roads are the key to any country's development as this saves in travel time, safety of passengers and delivery of local farm produce to market on time. Rural roads are the key channels to access the primary services like schools, hospitals and other social amenities. Rural roads are also the channels used by the Central Government for the transfer of policies to local governments for the benefit of the local people. However, these roads have their own challenges. According to Ngezahayo et al. (2019), the key challenge for the unpaved roads is lack of funds and the engineering expertise during the construction and maintenance stage (Ngezahayo et al., 2019).

Among the developing nations including Kenya, unpaved (gravel and earth) roads form a disproportionately large percentage of the road network when compared to the paved roads. In
Kenya, earth roads account for about $47 \%$ of the road network, the gravel roads have $38 \%$ while the surface-dressed and premix asphalt roads are $11 \%$ and $4 \%$ respectively (KeNHA, 2019). It is important to note that paving of roads is an expensive exercise, though pertinent, that competes for the deficient resources in the usually strained economies resulting in their easy neglect. The prohibitive cost of the binder used in surface dressing, and the preparation of asphalt concrete, as well as the road making process are some of the reasons cited for the high cost of road paving.

Though gravel roads are better than the do-nothing case i.e., earth roads, these roads are not without construction and maintenance when compared to the paved roads. The adverse effects of rains, such as surface erosion, of poorly drained gravel roads compromises driving comfort or at worst; renders the roads impassable. On the other hand, trafficrelated activities generate dust and when this is aided by the lifting and transport actions of wind, there is further deterioration of the gravel road surface.

Most of the earth and gravel roads are in rural areas which are agricultural lands. The most significant problem associated with gravel and earth roads is dust emission, which contributes to the deterioration of the road surface hampering movement of people 
and goods (mostly agricultural produce). Most agricultural products are perishable e.g., vegetables, milk, peas, tomatoes, eggs, cereals etc. which spoils due to poor transport infrastructure. In addition, the dust causes road safety, human health and the environmental quality issues (Edvardsson, 2010). Dust also destroys the flora along the roads especially during the dry season which leads to low farm produce and the aesthetics of the environment.

In order to minimize dust emission dust suppressants are applied annually (Edvardsson, 2010). Calcium chloride and magnesium chloride are most commonly used for dust control on gravel roads. Affinity for moisture from the atmosphere helps form a crust and hold the road fines into the aggregate surface. The performance of magnesium chloride and calcium chloride are highly sensitive on temperature, relative humidity, rainfall and traffic. However, the use of calcium chloride and magnesium chloride have disadvantages. For instance, calcium chloride is corrosive to vehicles and application equipment and can create a slippery surface when applied leading to reduced skid resistance. Calcium chloride is soluble in water, hence, it is easily washed or leached away reducing its performance in dust control. Solid calcium chloride is exothermic; hence, high precautions are needed during the application. Magnesium chloride and calcium chloride have similar characteristics. Magnesium chloride is more sensitive to weather conditions, requiring temperatures above $20^{\circ} \mathrm{C}$ and relative humidity above $32 \%$ to be effective hence, not effective in cold regions (GRT, 2016).

As a result, there have been numerous recent technological advancements in stabilization of soils using the eco-friendly (green) and readily available materials. In many Kenyan rural homes and in most African countries, fresh cow dung (FCD) is used as dust suppressants in madhouses. The FCD is mixed with water to form a paste in some instances an insecticide is added, the paste is evenly smeared on earth surfaces, then it is left to dry. This controls dust and ingress by the rainwater. Therefore, FCD has dust control potentials. Hence, this study seeks to explore the mechanical and binding potentials of FCD for gravel roads construction.

\section{MATERIALS AND METHOD}

\section{Sample Collection and Preparation}

The gravel soil sample used for this investigation was collected from a used borrow pit at Membley (37M 268108.00 m E 9871211.00 mS), Kiambu County at a depth of $1.2 \mathrm{~m}$ using the method of disturbed sampling.

The FCD in form of cakes were collected from dairy farm at the University of Nairobi, Upper Kabete Campus (College of Agriculture and Veterinary Sciences - CAVS). The FCD cakes were pounded lightly using mortar and pestle. All the foreign materials i.e., natural vegetable matter and stones were removed through sieving with $10 \mathrm{~mm}$ sieve but retained on $5 \mathrm{~mm}$ sieve.

\section{Methods of Testing}

Figure 1 shows the procedure used in this study. The chemical and physical composition of the prepared FCD was analysed using relevant test methods (Table 1). The Index properties of gravel soil sample was also determined in accordance with relevant test methods (Table 2). 
Figure 1: Methodology Chart

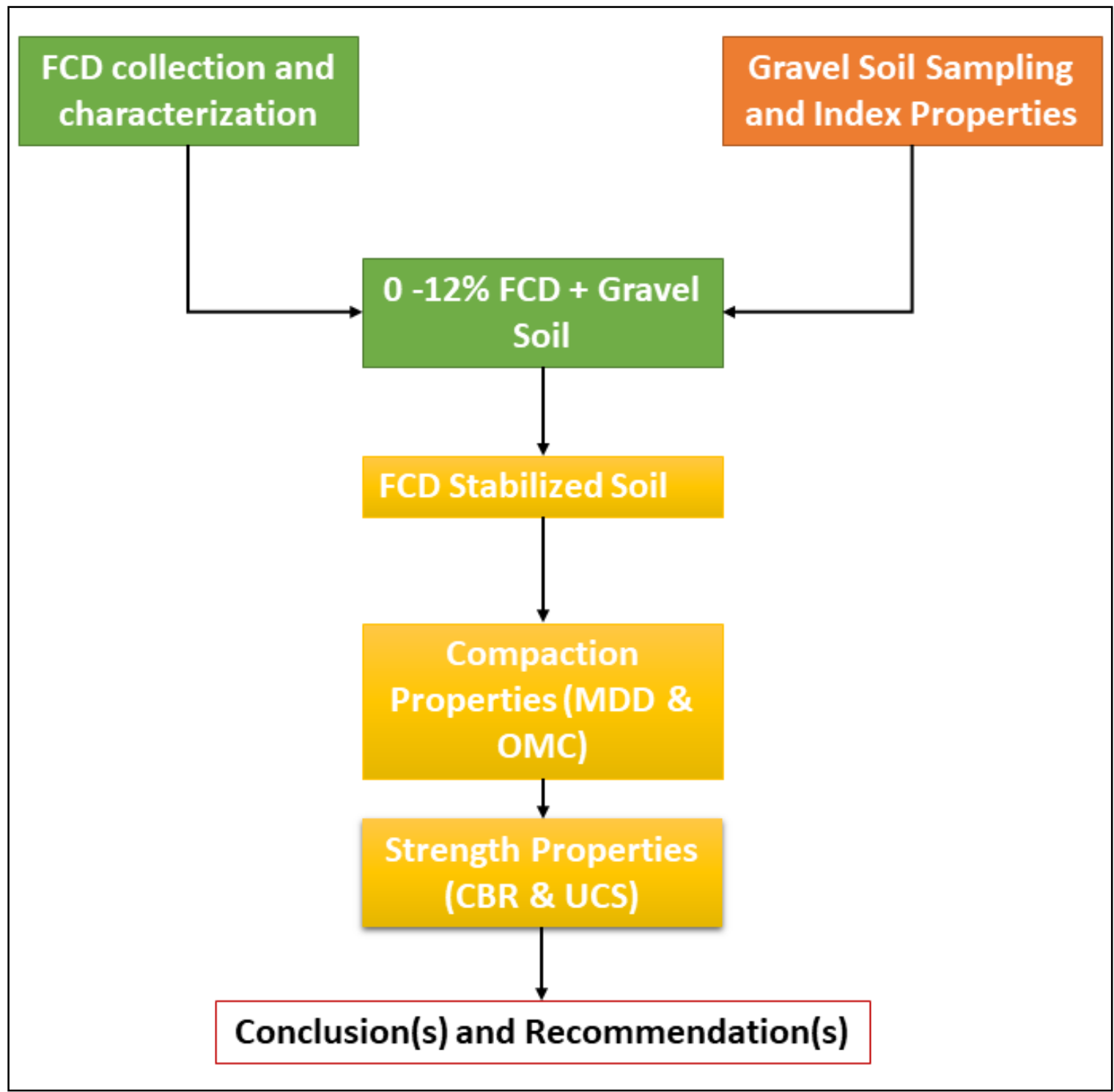

The effect of FCD on gravel soils was determined at various percentages $(0 \%, 3 \%, 6 \%, 9 \%$ and $12 \%)$ by weight. The compaction properties and the plasticity index were determined in accordance with BS 1377-4, 1990 and BS 1377-2, 1990 respectively. Specimens for UCS and CBR tests were prepared at OMC and MDD for soil - FCD. The CBR tests were conducted as specified in (ASTM D 1883-07,
2007), where the compressed samples were soaked for four (4) days before testing at a constant loading.

\section{RESULTS AND DISCUSSIONS}

\section{Identification of FCD}

The following results for particle size distribution were obtained as shown in Figure 2 for the FCD sample. 
Figure 2: Grading of gravel soil sample

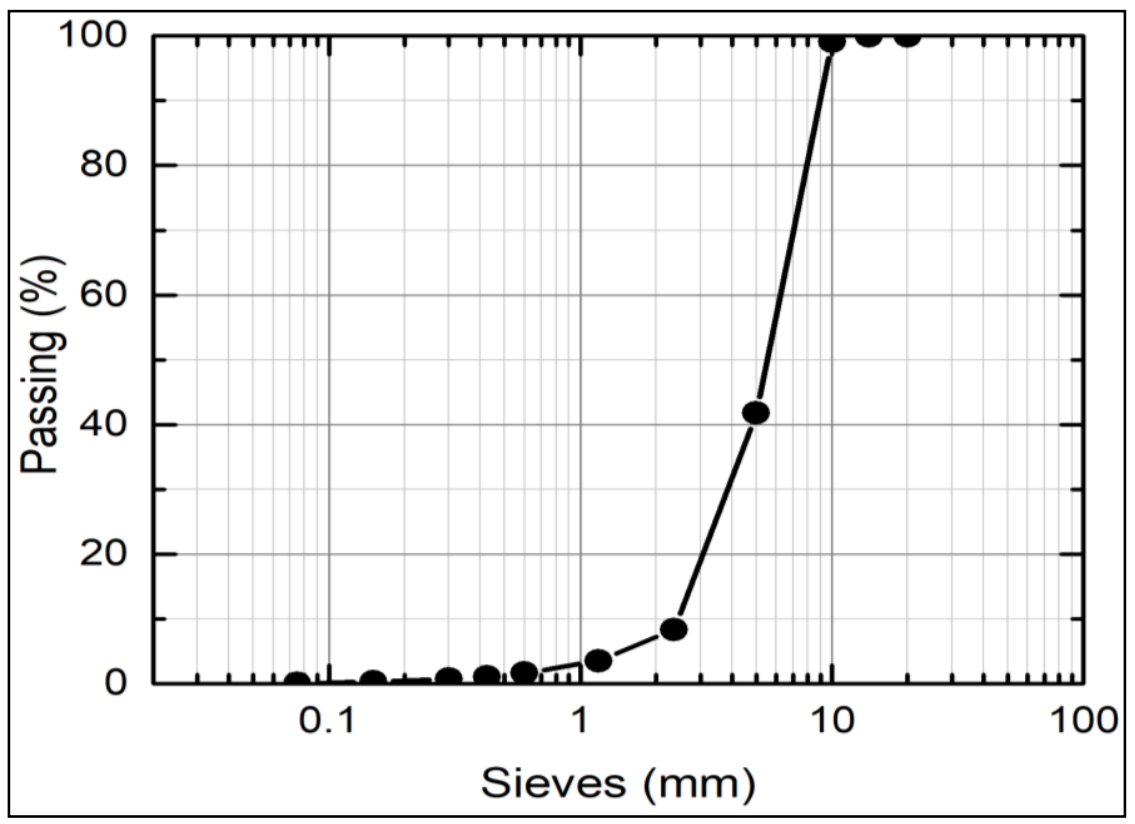

Table 1 indicates the results from the chemical composition for the FCD.

Table 1: Chemical composition of FCD sample

\begin{tabular}{llll}
\hline Parameters & Units & Values & Method \\
\hline $\mathrm{pH}$ & - & 10.20 & 1.2 .5 (water) \\
Ec & $\mathrm{dS} / \mathrm{m}$ & 2.5 & 1.2 .5 (water) \\
Nitrogen & $\%$ & 1.35 & Kjedhal \\
Organic Carbon & $\%$ & 18.50 & Walkley black \\
Organic matter & $\%$ & 31.80 & Calculated \\
Potassium & $\mathrm{ppm}$ & 3250 & Flame photometer \\
Phosphorous & $\mathrm{ppm}$ & 720.2 & Calorimetric \\
Sodium & $\mathrm{ppm}$ & 600 & Atomic absorption \\
Calcium & $\mathrm{ppm}$ & 2350 & Atomic absorption \\
Magnesium & $\mathrm{ppm}$ & 938 & Atomic absorption \\
Copper & $\mathrm{ppm}$ & 90 & Atomic absorption \\
Manganese & $\mathrm{ppm}$ & 194 & Atomic absorption \\
Zinc & $\mathrm{ppm}$ & 108 & Atomic absorption \\
Iron & $\mathrm{ppm}$ & 620 & Atomic absorption \\
Aluminium & $\mathrm{ppm}$ & Trace & Atomic absorption \\
Sulphate - S & $\mathrm{ppm}$ & 0.20 & Atomic absorption \\
Specific gravity & & 1.48 & - \\
\hline
\end{tabular}

Key: $p H$ - Hydrogen potential, Ec-Electro conductivity, ppm- parts per million

\section{Identification of Gravel soil}

Table 2 indicates the Index properties of natural soil as tested by various methods. The soil can be classified as A-2-7 according to AASHTO classification. The following results for particle size distribution were obtained as shown in Figure 3 for the gravel soil sample. According to gravel wearing course specifications (MoTC, 1987), grading of the 
soil sample is categorized as class 2 because percentage passing sieve no. $200(0.075 \mathrm{~mm})$ is $39.6 \%$. The soil sample is well graded.

Table 2: Index properties of natural soil

\begin{tabular}{lll}
\hline Test Description & Results & Method \\
\hline Soil sample collected from (Name & and & Kamiti (37M 268108.00 m \\
coordinates) & E 9871211.00 mS) & BS 1377-1, 1990 \\
Sieve analysis: & Figure 2 & \\
Natural moisture content (\%) & 9.2 & BS 1377-2, 1990 \\
Percentage passing B.S Sieve No. 200 & 39.6 & BS 1377-2, 1990 \\
Liquid Limit (\%) & 69 & BS 1377-2, 1990 \\
Plastic Limit (\%) & 35 & BS 1377-2, 1990 \\
Plasticity Index (\%) & 34 & BS 1377-2, 1990 \\
Shrinkage Index \% & 15 & BS 1377-2, 1990 \\
Free Swell \% & 0.18 & BS 1377-2, 1990 \\
Group Index & 1.6 & BS 1377: 1990 \\
AASHTO Classification & A-2-7 & BS 1377: 1990 \\
Unified system of classification (USC) & CH & AASHTO \\
Maximum Dry Density (kg/m $\left.{ }^{3}\right)$ & 1666 & ASTM D2487-11 \\
Optimum Moisture Content \% & 24.47 & BS 1377-4, 1990 \\
Unconfined Compressive Strength (kN/m $\left.{ }^{2}\right)$ & 207 & BS 1377-4, 1990 \\
California Bearing Ratio $(\%)$ & & ASTM D2166 \\
Unsoaked & 99 & BS 1377-5: 1990 \\
Soaked & 21 & BS 1377-5: 1990 \\
Specific Gravity & 1.82 & BS 1377-5: 1990 \\
Colour & Brown & BS 1377-2: 1990 \\
\hline
\end{tabular}

Figure 3: Grading of gravel soil sample

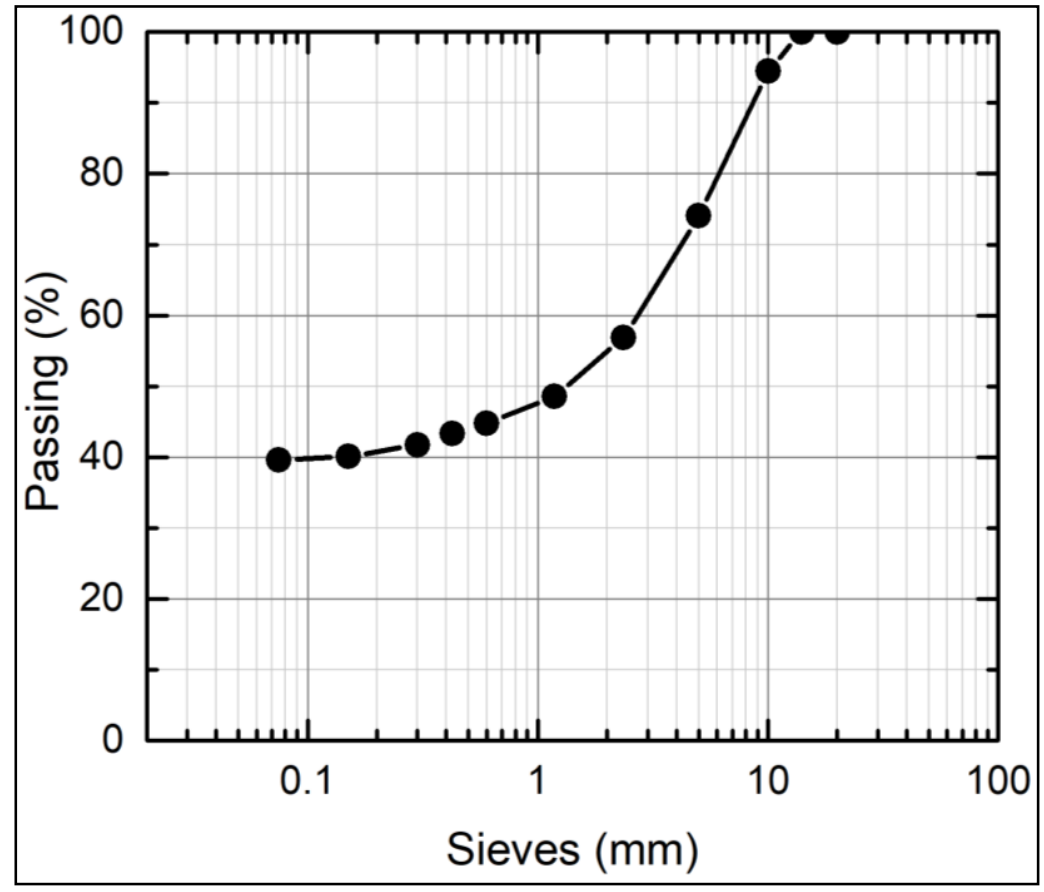

27 | This work is licensed under a Creative Commons Attribution 4.0 International License. 


\section{Properties of FCD - Soil mixture}

The following results for particle size distribution were obtained as shown in Figure 4 for the stabilized material at different percentages.

\section{Figure 4: Grading of soil-FCD mixture}

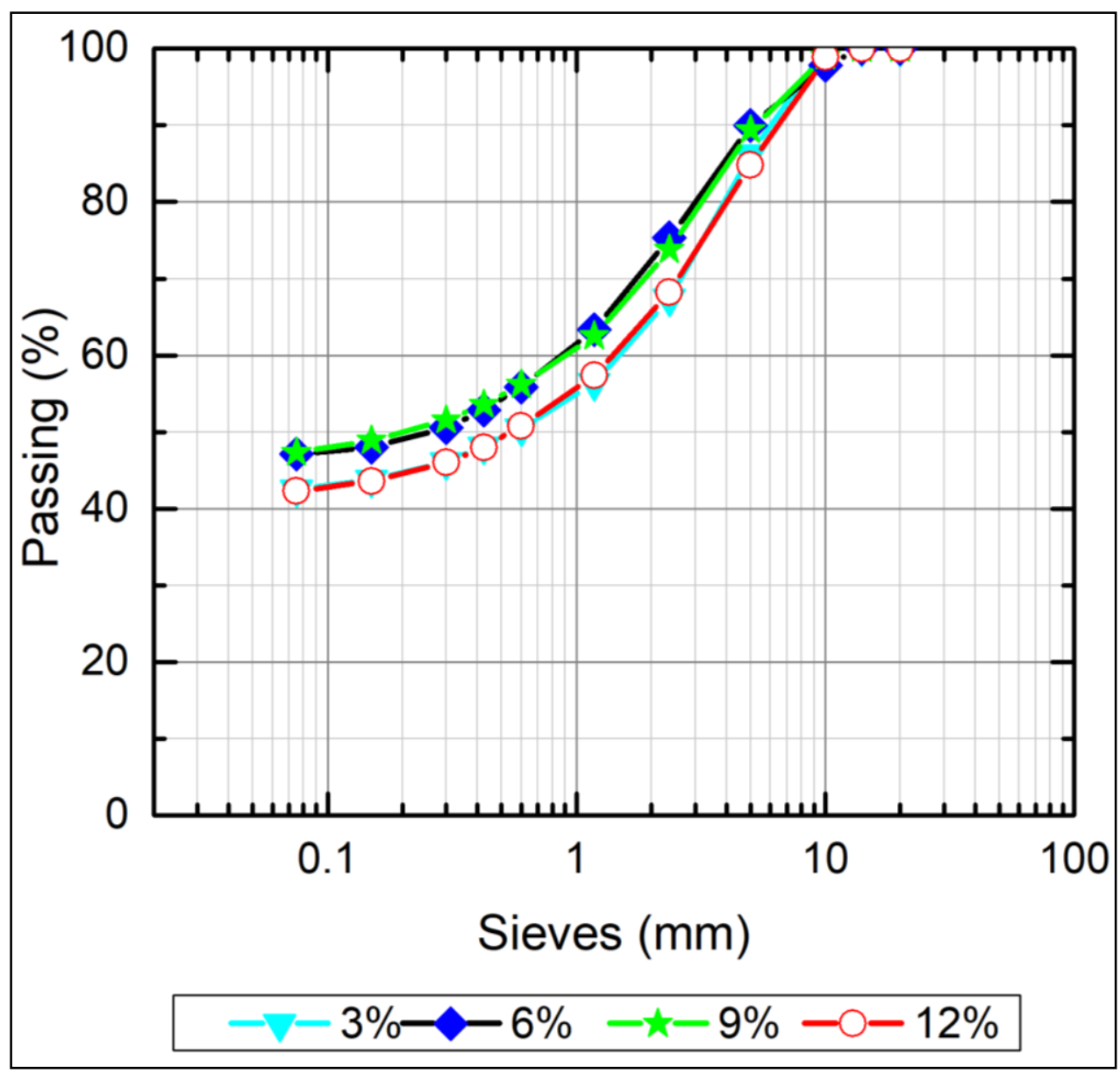

The results show that the $3 \% \& 12 \%$ mixtures have similar grading curves, likewise $6 \%$ \& $9 \%$ mixtures. The $3 \% \& 12 \%$ grading curves are closer to the natural gravel material grading curve. At $3 \%$ FCD is less therefore the grading curve is nearer to the natural gravel grading curve. The $6 \%$ \& $9 \%$ FCD have more fines compared to the rest. This can be attributed to the increase in fines from FCD. At $12 \%$ FCD the grading curve is similar to $3 \%$, this can be attributed to coagulating and conglomeration of the excess FCD.

\section{Atterberg Limits}

Table 3 indicates the values of the Atterberg limits for various percentages of the stabilized material. From gravel soil sample to $6 \%$ stabilized material, the liquid limit and plasticity index increases gradually and decreases with further increase in FCD. This can be attributed to an increase in fine materials which requires more water. From gravel soil sample to $9 \%$ stabilized material, the plastic limit and linear shrinkage increases gradually and decreases with further increase in FCD. This can

28 This work is licensed under a Creative Commons Attribution 4.0 International License. 
also be attributed to an increase in fine materials

which also requires more water.

Table 3: Atterberg Limits

\begin{tabular}{lllll}
\hline Stabilized material & Liquid limit & Plastic limit & Plasticity Index & Linear shrinkage \\
\hline $3 \%$ FCD & 71 & 37 & 34 & 17 \\
6\% FCD & 73 & 37 & 36 & 17 \\
9\% FCD & 70 & 41 & 29 & 14 \\
12\% FCD & 67 & 39 & 28 & 13 \\
\hline
\end{tabular}

\section{Effects of FCD on Gravel Soil Compaction}

Table 4 shows the OMC and MDD results obtained at different dosages of FCD. The results in indicates that the OMC increases with increase in FCD content from $25.25 \%$ at $3 \%$ FCD to $29.5 \%$ at $12 \%$ FCD. This can be attributed to an increase in fine materials, which requires more water for compaction. Fine materials have the high surface area to volume ratio which absorbs more water. The MDD decreases from $1666 \mathrm{~kg} / \mathrm{m}^{3}$ of natural gravel(NEAT) to $1474 \mathrm{~kg} / \mathrm{m}^{3}$ at $12 \% \mathrm{FCD}$. This can be explained by the more we replace the natural soil with FCD $\left(1420 \mathrm{~kg} / \mathrm{m}^{3}\right)$ which is lighter compared to natural soil $\left(1820 \mathrm{~kg} / \mathrm{m}^{3}\right)$, thus, the low densities of the stabilized material. In addition, increase in OMC reduces the densities of the stabilized material as water replaces the fines. With increase in stabilizer (FCD) and increase in OMC it results to the low values of MDD compared to natural gravel.

\section{Effects of FCD on Gravel Soil Strength}

\section{California Bearing Ratio}

Figure 5 shows the results of the CBR values for seven (7) samples at different dosages of FCD. At $3 \%$ FCD CBR values were similar to natural soil (NEAT) of $21 \%$. At $6 \%$ FCD, CBR was maximum at $53 \%$ and thereafter it dropped with further increase in the dosages of FCD.

Table 4: Effects of FCD on Gravel Soil Compaction.

\begin{tabular}{lll}
\hline Stabilized material & OMC $(\boldsymbol{\%})$ & MDD $\left(\mathbf{k g} / \mathbf{m}^{\mathbf{3}}\right)$ \\
\hline NEAT & 24.47 & 1666 \\
$3 \%$ FCD & 25.25 & 1613 \\
6\% FCD & 26.39 & 1553 \\
$9 \%$ FCD & 28.31 & 1532 \\
$12 \%$ FCD & 29.5 & 1474 \\
\hline
\end{tabular}

With $9 \%$ FCD, CBR values were lower than $6 \%$ FCD but higher than 3\% FCD. At $12 \%$ FCD, the CBR values were undulating between $3 \%$ \& $6 \%$, but, it never surpassed 6\% FCD. At 3\% FCD there is less fibres hence no much binding of the material hence low strength. At increased percentage $(6 \%$ FCD) there is much binding of the materials hence high strength. With the increased $9 \%$ FCD there is reduction in the natural soil hence low strength as compared to $3 \%$ FCD but higher than NEAT. With further increase in FCD (12\%) the CBR values are undefined. This is due to much of FCD replacing the natural soil hence low strength. Therefore $6 \%$ FCD results into the maximum CBR values while FCD dosages higher than $9 \%$ the outcome is undefined. 
Figure 5: CBR Values

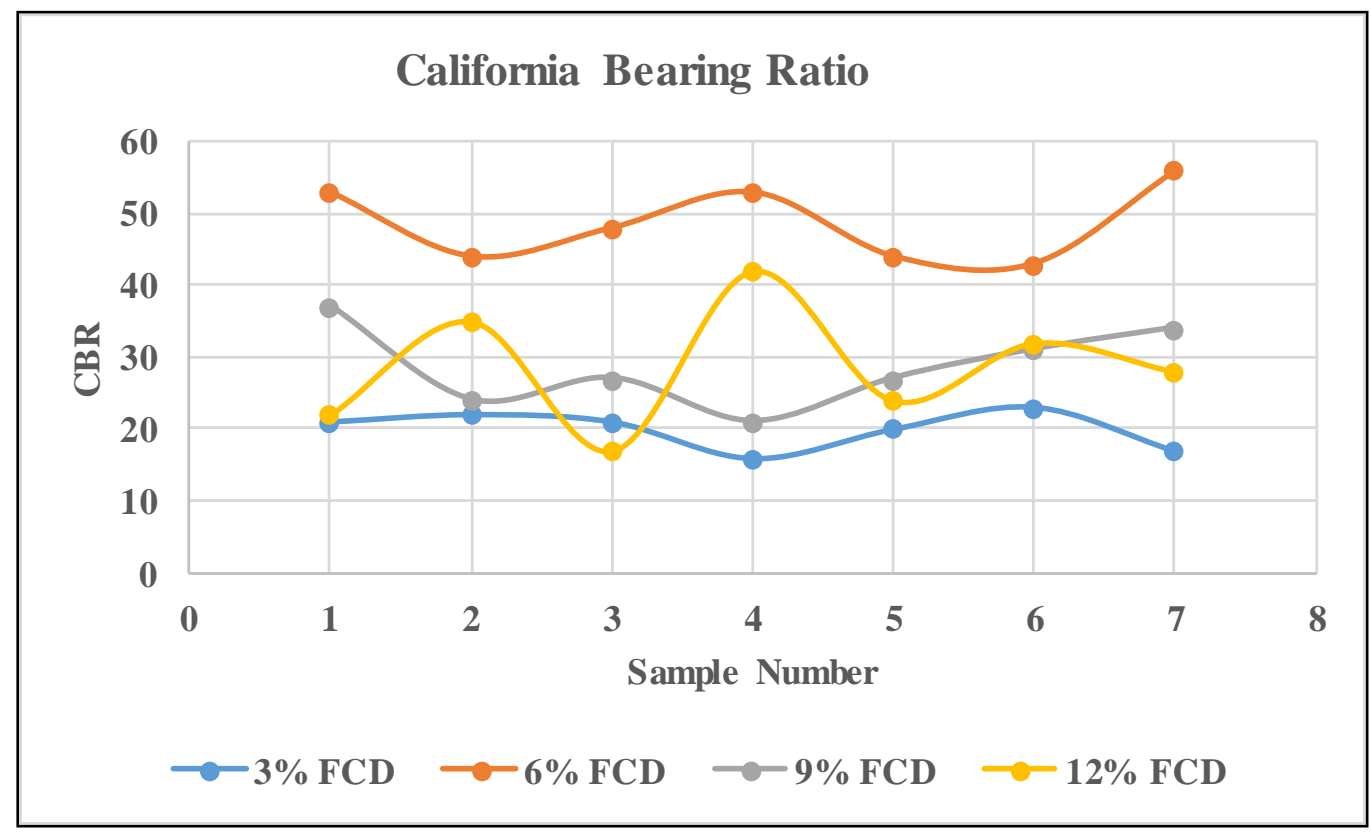

\section{Unconfined Compressive Strength}

Figure 6 shows the results of the UCS values for seven (7) samples at different dosages of FCD. The UCS value obtained for natural soil was $207 \mathrm{kN} / \mathrm{m}^{2}$. The UCS values increases with the increase in the
FCD content to a maximum of $257 \mathrm{kN} / \mathrm{m}^{2}$ at $6 \%$ FCD. This can be attributed to the fibres in FCD binding the gravel hence increase in strength. Further increase in FCD content leads to a decrease in UCS. This is due to the increase in the fines from FCD.

\section{Figure 6: UCS Values}

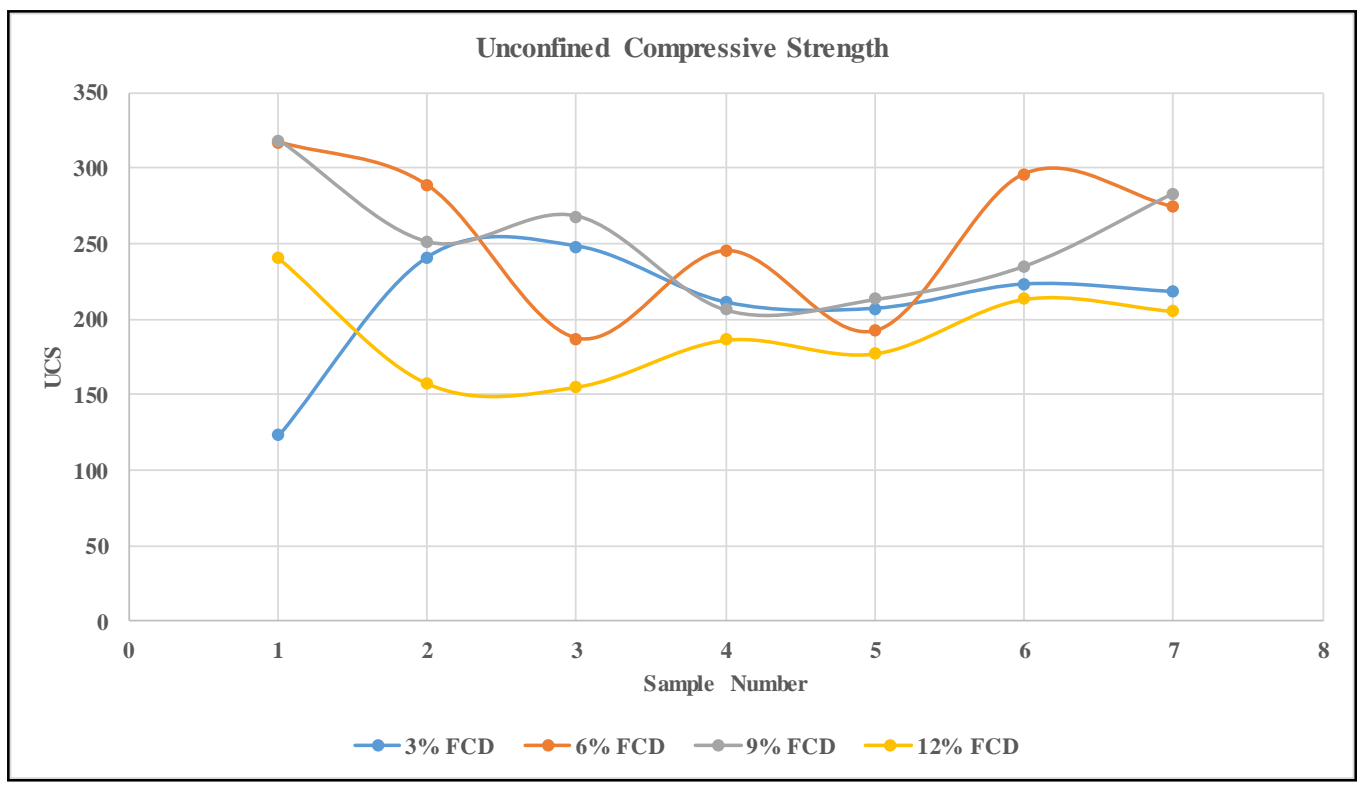

30 | This work is licensed under a Creative Commons Attribution 4.0 International License. 


\section{CONCLUSIONS AND RECOMMENDATIONS}

\section{Conclusions}

The mechanical and binding potentials of FCD for Gravel Roads Construction has been investigated. The following are the findings:

- The FCD used contains $31.8 \%$ of fibre which contributes to the binding properties of FCD.

- The Index properties of natural soil shows the soil can be classified as A-2-7 according to AASHTO classification.

- The $3 \%$ \& $12 \%$ soil-FCD mixtures have a similar grading curves, likewise $6 \%$ \& $9 \%$ mixtures.

- The liquid limit and plasticity index increases gradually and decreases with further increase in FCD up to $6 \%$.

- The plastic limit and linear shrinkage increases gradually and decreases with further increase in FCD up to $9 \%$.

- The OMC increases with increase in FCD content from $25.25 \%$ at $3 \%$ FCD to $29.5 \%$ at $12 \%$ FCD.

- The MDD decreases from $1666 \mathrm{~kg} / \mathrm{m}^{3}$ of natural gravel (NEAT) to $1474 \mathrm{~kg} / \mathrm{m}^{3}$ at $12 \%$ FCD.

- At 3\% FCD, CBR (21\%) value is similar to natural soil while, maximum CBR $(53 \%)$ was obtained at $6 \%$ FCD thereafter, further increase in the dosages of FCD resulted to the decrease in CBR. Higher dosages of FCD (12\%), the CBR values are undefined.

- The UCS value for natural soil is $207 \mathrm{kN} / \mathrm{m}^{2}$. The UCS values increases with the increase in the FCD content to a maximum of $257 \mathrm{kN} / \mathrm{m}^{2}$ at $6 \%$ FCD. Further increase in FCD content leads to a decrease in UCS.

\section{Recommendations}

- It is recommended that we use $6 \% \mathrm{FCD}$ on natural soil for the stabilization.

- It is recommended to use FCD passing sieve 10 but retained on sieve $5 \mathrm{~mm}$ due to high fibre content.

- Scientific studies should be carried out to determine how long the FCD gravel soil would last since the FCD is an organic material, especially in adverse weather conditions i.e., rainy season.

- Scientific studies are recommended to determine the fibre tensile strength of FCD under different traffic loading conditions.

- Pilot studies are required before the utilization of FCD stabilization on gravel roads construction.

\section{ACKNOWLEDGMENT}

The authors would like to acknowledge the National Research Fund (NRF) for the financial support which made this research possible.

\section{Declaration of Conflict of Interest}

There are no conflict of interest

\section{REFERENCES}

Edvardsson, K. (2010). Evaluation of Dust suppressants for Gravel Roads: Methods Development and Efficiency Studies. Doctoral Thesis. Stockholm: Royal Institute of Technology.

Ngezahayo, E., Burrow, M., \& Ghataora, G. (2019). Rural Roads -roles, challenges and solutions for Sub-Saharan Africa's sustainable development. International Journal of Latest Engineering and Management Research (IJLEMR), 4 (10), 70-79.

31 This work is licensed under a Creative Commons Attribution 4.0 International License. 
East African Journal of Engineering, Volume 3, Issue 1, 2021

Article DOI: https://doi.org/10.37284/eaje.3.1.350

GRT. (2016, January 31). Dust Control on Gravel

Roads. Retrieved from Global Road

Technology:

https://globalroadtechnology.com/dust-control-

on-gravel-roads/

KeNHA. (2019, September 19). Map Classification: Kenya National Highways Authority. Retrieved from Kenya National Highways Authority,https://www.kenha.co.ke/i ndex.php/road-network

MoTC. (1987). Road design manual part III. Nairobi: Ministry of Transport and Communication.

32 This work is licensed under a Creative Commons Attribution 4.0 International License. 